\title{
Evaluasi Keterlambatan Pengiriman Barang dengan Menggunakan Metode Six Sigma
}

\author{
Somadi ${ }^{\text {a, } 1, *}$ \\ ${ }^{a}$ Politeknik Pos Indonesia, Jl. Sariasih No.54, Kota Bandung 40151, Indonesia \\ ${ }^{1}$ somadi@poltekpos.ac.id*
}

\section{ARTICLE INFO \\ Article history \\ Received 2020-07-20 \\ Revised 2020-09-29 \\ Accepted 2020-10-31}

Keywords

Delay in Delivery

Improvement Design

Six Sigma

DMAIC

\begin{abstract}
One of the things that is usually the basis of consumers choosing a company is the quality of service. So the quality of service becomes important because it will have a direct impact on companies such as PT. $Z$. One type of service provided is in the form of on time delivery. But in practice the delivery time is not always achieved, sometimes there is still a delay. This study aims to identify the types of shipping delays that often occur and the factors causing delays in shipping and to design improvement strategies to minimize the occurrence of shipping delays at $P T$. Z. The method used in this study is to use the Six Sigma method with the DMAIC approach. Based on the results of the study that the type of delay that often occurs and needs to be addressed is the delay in sending documents. The factors that cause delays in shipping are caused by delays in the stuffing plan, errors in informing shipping instructions to EMKL, ship booking delays, miss communication, shortage of trucking fleets and unorganized work spaces. The strategies to minimize the occurrence of delays in the delivery of goods namely adding labor, working in a focused and meticulous manner, establishing active interaction between divisions, communicating various shipping information to the EMKL, finding new trucking fleet vendors, and creating a comfortable and neat working atmosphere.
\end{abstract}

\section{A. PENDAHULUAN}

Indonesia sebagai salah satu negara terbesar di dunia memiliki berbagai peranan penting di antara negara-negara yang ada di Asia Tenggara, yakni salah satunya negara yang memiliki industri manufaktur terbesar. Pada skala nasional, sektor ini memberikan sumbangsih berupa peningkatan perekonomian sebesar 20,27\% dengan menggeser peran commodity based menjadi manufacture based. Dengan berlimpahnya kondisi industri manufaktur di Indonesia membuat persaingan antar perusahaan manufaktur menjadi sangat ketat.

PT. Z merupakan salah satu perusahaan manufaktur kayu terpadu di Indonesia yang memproduksi kayu log yang diolah menjadi produk plywood, produk wood working dan produk particle board. Untuk menghadapi persaingan yang ketat, maka PT. Z perlu memberikan pelayanan yang maksimal kepada konsumen. Berbagai aspek yang menjadi pertimbangan konsumen untuk memilih dan memutuskan untuk membeli produk yang dihasilkan oleh perusahaan manufaktur. Salah satu hal yang biasanya menjadi dasar konsumen memilih suatu perusahaan yaitu kualitas pelayanan. Kualitas pelayanan merupakan upaya pemenuhan kebutuhan dan keinginan konsumen serta ketepatan penyampaiannya dalam mengimbangi harapan konsumen. Oleh karena itu kualitas pelayanan diberikan kepada konsumen harus berfungsi untuk lebih memberikan kepuasan yang maksimal.

Kualitas pelayanan menjadi penting karena akan berdampak langsung kepada perusahaan. Jika kualitas pelayanan perusahaan baik, maka akan tercapai kepuasan pelanggan. Kepuasan merupakan perasaan senang atau kecewa yang diperlihatkan oleh seseorang yang berasal dari perbandingan antara kesan terhadap kinerja (atau hasil) suatu produk dengan harapannya. Jika pelanggan merasa puas maka konsumen akan menjadi pelanggan setia. Dan sebaliknya, apabila pelanggan merasa 
tidak puas terhadap apa yang dialaminya, maka kemungkinan pelanggan akan peralih ke perusahaan lain. Dengan demikian, maka kualitas pelayanan perusahaan harus dijaga karena kualitas pelayanan akan mempengaruhi kepuasan dan loyalitas konsumen, karena apabila kualitas pelayanan kurang baik, maka akan mengakibatkan pelanggan tidak puas yang akan berimbas pada penurunan profit perusahaan karena pelanggan akan memilih produk perusahaan lain. Maka dari itu, sangat penting untuk mempertimbangkan aspek kepuasan pelanggan terkait kualitas pelayanan yang diberikan. Kualitas pelayanan sering diukur menggunakan lima dimensi yaitu keandalan, jaminan, bukti fisik, empati dan daya tanggap.

Dalam memberikan pelayanan kepada konsumen, keandalan menjadi salah satu fokus perusahaan untuk memuaskan konsumen. Keandalan yang diberikan oleh perusahaan yaitu berupa ketepatan waktu pengiriman. Untuk memenuhi keinginan pelanggan di bisnis logistik, ada beberapa hal yang perlu diperhatikan dalam menawarkan dan mengelola layanan pelanggan salah satunya yaitu layanan pengiriman, mengacu pada frekuensi pengiriman, lot pengiriman, penentuan waktu, penentuan lokasi pengiriman, dan lain-lain. Namun dalam praktiknya ketepatan waktu pengiriman barang atau dokumen tidak selalu dapat tercapai, karena terkadang masih terjadi keterlambatan. Apabila keterlambatan ini terus terjadi maka perusahaan akan mengalami kerugian baik dari internal yaitu barang dapat menumpuk di gudang maupun kerugian eksternal yaitu adanya komplain dari customer karena barang atau dokumen tidak sampai tepat waktu. Faktor penyebab munculnya rasa ketidakpuasan terhadap sesuatu, baik itu produk maupun jasa disebabkan karena tidak sesuai antara harapan dan kenyataan yang dialami, dan biasanya layanan selama proses menikmati jasa tidak memuaskan.

Dari uraian tersebut diatas menunjukkan bahwa kecacatan kualitas pelayanan perlu dianalisis dengan tujuan untuk memperbaiki pelayanan yang diberikan oleh perusahaan kepada pelanggannya agar terciptanya kepuasan pelanggan. Pada dasarnya pelanggan akan puas apabila mereka menerima nilai sebagaimana yang mereka harapkan. Oleh sebab itu perusahaan perlu mengidentifikasi penyebab keterlambatan pengiriman baik barang atau dokumen agar sesuai dengan kualitas pelayanan yang diharapkan yaitu pengiriman barang atau dokumen sampai tepat pada waktu, dan tidak ada kesalahan pada jenis maupun banyaknya barang yang dikirim, sehingga membuat pelanggan merasa puas .

Salah satu cara untuk melakukan perbaikan atau peningkatan kualitas dalam suatu perusahaan adalah dengan menggunakan metode six sigma. Penerapan six sigma sendiri pada umumnya menggunakan konsep DMAIC untuk menyusun langkah-langkah guna mengimplementasikan metode six sigma yang dimulai dari tahap define, tahap measure, tahap analyze, tahap improve, dan tahap control. Hal ini disebabkan karena DMAIC bertujuan untuk memetakan masalah, peluang, proses, dan persyaratan pelanggan sehingga harus diverifikasi dan diperbaharui pada setiap langkahnya. Dengan demikian, tujuan dalam penelitian ini yakni untuk mengidentitifkasi jenis keterlambatan pengiriman yang sering terjadi dan faktor penyebab terjadinya keterlambatan pengiriman serta untuk merancang strategi perbaikan untuk meminimalisir terjadinya keterlambatan pengiriman di PT. Z.

\section{B. METODE}

Metode yang digunakan pada penelitian ini menggunakan pendekatan kuantitatif. Teknik pengumpulan data menggunakan wawancara dan studi dokumentasi. Adapun teknik analisis yang digunakan yakni adalah Six Sigma dengan konsep DMAIC. Six Sigma merupakan suatu disiplin pendekatan melalui data dan suatu metodologi untuk mengurangi atau meniadakan kesalahan (defect) dalam semua proses pelayanan. Six sigma merupakan suatu pendekatan untuk mengurangi atau meniadakan kesalahan dalam proses pelayanan. Sementara itu, DMAIC merupakan suatu proses yang berfokus pada pengukuran guna meningkatkan kualitas kualitas menuju target six sigma.

Metode six sigma disusun dengan DMAIC yang merupakan singkatan dari define, measure, analyze, improve, dan control. Pada setiap tahapan D-M-A-I-C memiliki tujuan dan perangkat (tools) yang berbeda. Berikut adalah langkah-langkah analisis data dalam penelitian ini: 


\section{Define}

Define merupakan tahap identifikasi awal guna melihat permasalahan terjadi pada perusahaan. Hal ini disebabkan karena define dilakukan untuk mengidentifikasi variabel penyebab keterlambatan pada obyek penelitian. Tahap define dilakukan dengan cara pembuatan deskripsi proses produksi dengan pembuatan diagram SIPOC dan penentuan critical to quality. Sehingga pada tahap define dalam penelitian ini akan menggunakan diagram SIPOC dan critical to quality (CTQ).

a. SIPOC. Analisis SIPOC digunakan untuk menyajikan sekilas aliran kerja mulai dari supplier, input, proses, output, dan customer.

b. Critical To Quality (CTQ). Adapun langkah-langkah dalam $C T Q$ ini adalah:

1) Menghitung Critical To Quality (CTQ)

Pada tahap ini yaitu menentukan kriteria yang menimbulkan atau memiliki potensial untuk menimbulkan kegagalan atau kecacatan.

2) Menetapkan Critical To Quality (CTQ)

Pada tahap $C T Q$ ini menetapkan permasalahan yang paling sering terjadi.

c. Diagram Pareto. Diagram pareto bertujuan untuk memperjelas faktor yang paling penting atau yang paling besar dari beberapa faktor yang ada, dan juga untuk menentukan critical to quality dan selanjutnya dilakukan pengukuran menggunakan peta kendali yang menghitung batas bawah dan batas atas guna mengetahui apakah perlu dilakukan proses perbaikan [9]. Dengan demikian bahwa diagram pareto digunakan untuk memetakan permasalahan yang paling besar berdasarkan hasil analisis CTQ.

2. Measure

Pada tahap ini berfokus pada pemahaman kinerja proses yang dipilih untuk dilakukan perbaikan. Tahapan ini terdiri dari beberapa tahapan di dalamnya, yaitu:

a. Perhitungan $D P M O$ dan kapabilitas Sigma. Perhitungan nilai $D P M O$ dilakukan dengan cara sebagai berikut:

$\mathrm{DPO}=\frac{\text { Jumlah Kecacatan }}{\text { Jumlah Total Unit } x \text { peluang }}$

\section{DPMO $($ Deffect per Million Opportunities $=$ DPO $\times 1.000 .000$}

b. Peta Kendali. Peta kendali merupakan teknik pengendali proses pada jalur yang digunakan guna menaksir parameter suatu proses produksi. Control chart merupakan alat untuk mengevaluasi suatu proses, apakah dalam keadaan terkendali atau tidak dengan bantuan salah satunya peta kendali $\mathrm{P}$ sehingga akan diketahui apakah produk yang mengalami kecacatan masih dalam batas yang disyaratkan atau tidak. Berikut adalah langkah-langkah dalam pembuatan peta kendali:

1) Menghitung persentase keterlambatan setiap bulan dengan rumus sebagai berikut:

$$
\mathrm{p} 1 \quad=\frac{x 1}{n 1}
$$

Keterangan:

$$
\begin{array}{ll}
\mathrm{p} & =\text { Proporsi keterlambatan } \\
\mathrm{x} & =\text { Jumlah keterlambatan per bulan } \\
\mathrm{n} & =\text { Jumlah pengiriman per bulan }
\end{array}
$$

2) Menghitung persentase keterlambatan rata-rata atau center (CL) sebagai garis tengah pada diagram kendali dengan rumus:

$$
\begin{aligned}
& \text { CL } \quad=\frac{\sum x}{\sum n} \\
& \text { Keterangan: } \\
& \begin{array}{ll}
\sum x \quad=\text { Jumlah total keterlambatan } \\
\sum n \quad=\text { Jumlah total kiriman }
\end{array}
\end{aligned}
$$


3) Menghitung Batas Kendali Atas atau Upper Control Limit (UCL) dan Batas Kendali Bawah atau Lower Control Limit $(L C L)$ dengan rumus:

$$
\begin{array}{ll}
\mathrm{UCL} & =\mathrm{CL}+3 \frac{\sqrt{C L(1-C L)}}{n i} \\
\mathrm{LCL} & =\mathrm{CL}-3 \frac{\sqrt{C L(1-C L)}}{n i}
\end{array}
$$

\section{Analyze}

Tahap analyze berfungsi untuk menggali informasi akar masalah terhadap permasalahan yang terpilih dari analisis sebelumnya. Tahap analyze digunakan untuk mencari penyebab terjadinya kerusakan dengan menggunakan teknik analisis fishbone. Analisis diagaram fishbone atau diagram tulang ikan juga dapat digunakan untuk menganalisa penyebab permasalahan kerusakan barang kiriman yang terjadi.

\section{Improve}

Tahap improve bertujuan untuk merencanakan tindakan untuk meminimalisir terjadinya permasalahan pada perusahaan. Pada tahap ini akan melakukan identifikasi dan deskripsi tindakan perbaikan guna mencari usulan pemecahan masalah guna meningkatkan kualitas sesuai target dari perusahaan agar lebih baik dan efisien. Teknik analisis pada tahap ini menggunakan metode $5 \mathrm{~W}+1 \mathrm{H}$. Adapun makna $5 \mathrm{~W}+1 \mathrm{H}$ dalam penelitian ini yaitu what bermakna apa permasalahan yang terjadi, when bermakna kapan rencana perbaikan dilaksanakan, where bermakna dimana rencana perbaikan tersebut dilaksanakan, why bermakna kenapa perlu dilakukan perbaikan, who bermakna siapa yang bertanggung jawab terhadap perbaikan, dan how bermakna bagaimana tata cara perbaikan yang dilakukan. Adapun tahapan-tahapan dalam menggunakan analisis $5 \mathrm{~W}+1 \mathrm{H}$ sebagai berikut:

1) What, bermakna apa permasalahan yang akan dilakukan perbaikan?

2) Why, bermakna kenapa perlu dilakukan perbaikan?

3) Where, bermakna dimana lokasi perbaikan akan dilakukan?

4) When, bermakna kapan perbaikan akan dilakukan?

5) Who, bermakna siapa yang bertanggungjawab terhadap perbaikan yang akan dilakukan?

6) How, bermakna bagaimana strategi untuk mengatasi permasalahan yang akan dilakukan perbaikan?

\section{Control}

Pada tahap control ini dilakukan pemantauan pada proses untuk memastikan perubahan yang telah dihasilkan telah sesuai dan dengan menjaga kondisi yang sudah ditetapkan pada fase improve. Pengendalian (control) dilakukan selama periode waktu tertentu untuk memastikan bahwa perbaikan yang dilakukan sudah baner-benar menjawab permasalahan yang ada.Tahap control juga dapat dikatakan sebagai tahap untuk memantau agar perencanaan alternatif perbaikan dapat diaplikasikan oleh perusahaan. Teknik analisis yang digunakan pada tahap ini yakni pembuatan Standard Operational Procedure (SOP).

\section{HASIL DAN PEMBAHASAN}

Berdasarkan data dari hasil pengumpulan data, maka dilakukan berbagai pengolahan dan analisis data. Berikut ini adalah hasil dan pembahasan terkait hasil pengolahan data yang telah dilakukan.

\section{Define}

Tahap define merupakan tahap untuk mengidentifikasi masalah dalam penelitian. Masalah yang dijelaskan dalam penelitian ini terkait dengan masalah keterlambatan dalam proses pengiriman yang terdiri dari keterlambatan pengiriman barang dan keterlambatan pengiriman dokumen yang terjadi di PT. Z. Berikut ini hasil analisis pada tahap define:
a. $S I P O C$ 
SIPOC merupakan seingkatan dari 5 elemen dalam sistem kualitas meliput Supplies, Inputs, Processes, Outputs, Customers. Berikut ini adalah diagram SIPOC proses pengiriman barang dan proses pengiriman dokumen pada PT. Z:

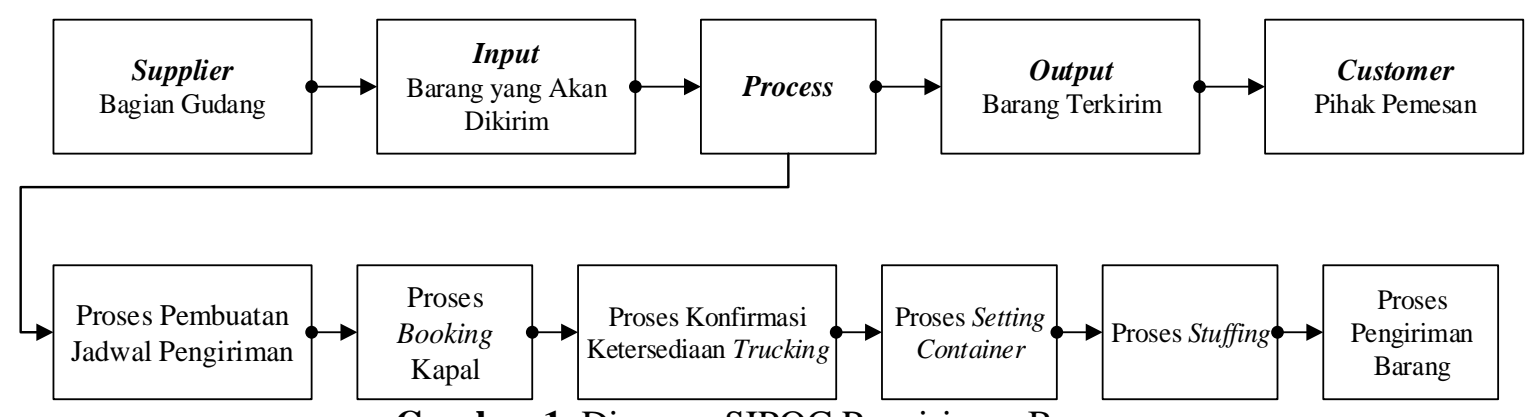

Gambar 1. Diagram SIPOC Pengiriman Barang

Sumber: Hasil Pengolahan Data, Tahun 2020

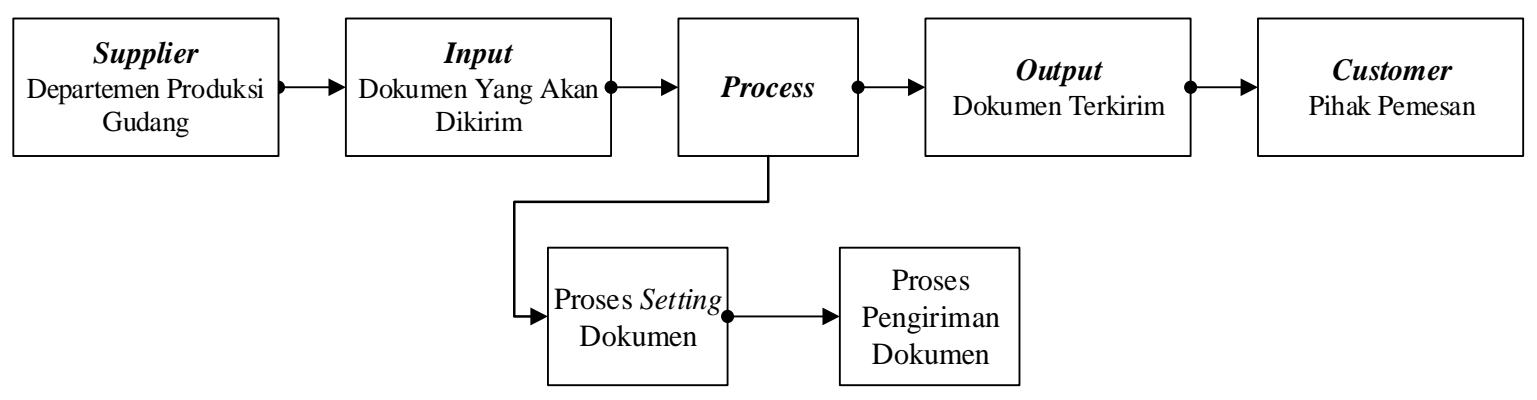

Gambar 2. Diagram SIPOC Pengiriman Dokumen

Sumber: Hasil Pengolahan Data, Tahun 2020

Berdasarkan Gambar 1 di atas, dapat dilihat proses pengiriman barang dan pada Gambar 2 dapat dilihat proses pengiriman dokumen. Output yang diharapkan dari kedua proses tersebut adalah ketepatan waktu pengiriman. Namun dalam pelaksanaannya, kedua proses pengiriman tersebut tidak selalu berjalan dengan lancar, terkadang juga terjadi kecacatan produk berupa keterlambatan pengiriman. Berikut adalah data keterlambatan pengiriman barang dan keterlambatan pengiriman dokumen pada PT. Z:

Tabel 1. Keterlambatan Pengiriman Barang Bulan September-November 2018

\begin{tabular}{|cccc|}
\hline Bulan & Realisasi & Aktual & Jumlah Tundaan Kontainer \\
\hline September & 207 & 159 & 48 \\
\hline Oktober & 233 & 172 & 61 \\
\hline November & 194 & 143 & 51 \\
\hline Jumlah & 634 & 474 & 160 \\
\hline
\end{tabular}

Sumber: Hasil Pengolahan Data, Tahun 2020

Tabel 2. Keterlambatan Pengiriman Dokumen Bulan September-November 2018

\begin{tabular}{|cccc|}
\hline Bulan & Realisasi & Aktual & Jumlah Tundaan Kontainer \\
\hline September & 42 & 38 & 4 \\
\hline Oktober & 67 & 64 & 3 \\
\hline November & 17 & 14 & 3 \\
\hline Jumlah & 126 & 116 & 10 \\
\hline
\end{tabular}

Sumber: Hasil Pengolahan Data, Tahun 2020

Pada tahap selanjutnya akan dilakukan perhitungan $C T Q$ untuk keterlambatan pengiriman barang dan keterlambatan pengiriman dokumen. 
b. Critical To Quality (CTQ)

Menghitung Critical To Quality (CTQ)

Perhitungan $C T Q$ pada tahap ini dilakukan dengan menggunakan check sheet. Check sheet yang bertujuan untuk memberikan informasi berupa nama produk yang mengalami kerusakan, banyaknya produk yang mengalami kerusakan, dan waktu pengamatan. Check Sheet yang dapat dilihat pada Tabel 4 di bawah ini:

Tabel 3. Check Sheet Keterlambatan Pengiriman Barang dan Keterlambatan Pengiriman Dokumen Bulan September-November 2019

\begin{tabular}{|c|c|c|c|}
\hline \multirow[b]{2}{*}{ Bulan } & \multicolumn{2}{|c|}{ Jenis Keterlambatan } & \multirow[b]{2}{*}{ Total } \\
\hline & $\begin{array}{c}\text { Keterlambatan Pengiriman } \\
\text { Barang }\end{array}$ & $\begin{array}{c}\text { Keterlambatan Pengiriman } \\
\text { Dokumen }\end{array}$ & \\
\hline September & $\begin{array}{c}\text { IIIII IIIII IIIII IIIII IIIII IIIII } \\
\text { IIIII IIIII IIIII III }\end{array}$ & IIII & 52 \\
\hline Oktober & $\begin{array}{l}\text { IIIII IIIII IIIII IIIII IIIII IIIII } \\
\text { IIIII IIIII IIIII IIIII IIIII IIIII I }\end{array}$ & III & 64 \\
\hline November & $\begin{array}{l}\text { IIIII IIIII IIIII IIIII IIIII IIIII } \\
\text { IIIII IIIII IIIII IIIII I }\end{array}$ & III & 54 \\
\hline Total & 160 & 10 & 170 \\
\hline
\end{tabular}

Sumber: Hasil Pengolahan Data, Tahun 2020

Setelah tabel check sheet di atas, selanjutnya yaitu dilakukan perhitungan untuk mengetahui persentase kumulatif sesuai dengan jenis keterlambatan. Perhitungannya adalah sebagai berikut:

a. Keterlambatan Pengiriman Barang

Persentase $\%=\frac{\text { Jumlah unit }}{\text { Jumlah frekuensi }} \times 100=\frac{160}{634} \times 100=94 \%$

b. Keterlambatan Pengiriman Dokumen

Persentase $\%=\frac{\text { Jumlah unit }}{\text { Jumlah frekuensi }} \times 100=\frac{10}{126} \times 100=6 \%$

Tabel 4. Persentase Keterlambatan Pengiriman Berdasarkan $C T Q$

\begin{tabular}{|clcccc|}
\hline No & Identifikasi masalah & Frekuensi & $\begin{array}{c}\text { Akumulasi } \\
\text { Frekuensi }\end{array}$ & $\begin{array}{c}\text { Persentase } \\
\text { dari Total }\end{array}$ & $\begin{array}{c}\text { Akumulasi } \\
\text { Persentase }\end{array}$ \\
\hline 1 & $\begin{array}{l}\text { Keterlambatan Pengiriman } \\
\text { Barang }\end{array}$ & 160 & 160 & $94 \%$ & $94 \%$ \\
\hline 2 & $\begin{array}{l}\text { Keterlambatan Pengiriman } \\
\text { Dokumen }\end{array}$ & 10 & 170 & $6 \%$ & $100 \%$ \\
\hline \multicolumn{2}{c}{ Total } & 170 & & $100 \%$ & \\
\hline
\end{tabular}

Sumber: Hasil Pengolahan Data, Tahun 2020

Menetapkan Critical To Quality (CTQ)

Untuk melakukan identifikasi $C T Q$ yang dikembangkan melalui spesifikasi yang bersumber dari check sheet dan standar spesifikasi yang ada di perusahaan.

Tabel 5. Karakteristik $C T Q$

\begin{tabular}{|clc|}
\hline No & \multicolumn{1}{c|}{$\boldsymbol{C T Q}$} & \multicolumn{1}{c|}{ Jenis Kerugian } \\
\hline 1 & Keterlambatan & - Terjadinya perubahan jadwal pengiriman dan barang terlambat \\
& $\begin{array}{l}\text { Pengiriman } \\
\text { Barang }\end{array}$ & - \\
\hline 2 & Keterlambatan & - \\
& $\begin{array}{l}\text { Pengiriman } \\
\text { Dokumen }\end{array}$ & \\
\hline
\end{tabular}

Sumber: Hasil Pengolahan Data, Tahun 2020 
Berdasarkan tabel di atas, dapat diketahui kerugian yang akan timbul akibat adanya keterlambatan pengiriman barang maupun keterlambatan pengiriman dokumen. Pada tahap ini, CTQ ditetapkan berdasarkan jenis keterlambatan yang paling sering terjadi. Jenis keterlambatan ini dikelompokkan menjadi 2 yaitu keterlambatan pengiriman barang dan keterlambatan pengiriman dokumen.

c. Diagram Pareto Berdasarkan $C T Q$

Diagram Pareto berfungsi untuk menentukan jenis permasalahan apa yang memiliki nilai paling potensial guna menentukan prioritas perbaikan system kerja. Pada tahap define telah dilakukan perhitungan $C T Q$ untuk mengetahi dan menentukan jenis keterlambatan yang paling dominan. Kemudian langkah selanjutnya adalah membuat diagram pareto berdasarkan perhitungan $C T Q$ tersebut. Berikut adalah Diagram Pareto untuk keterlambatan pengiriman barang dan keterlambatan pengiriman dokumen.

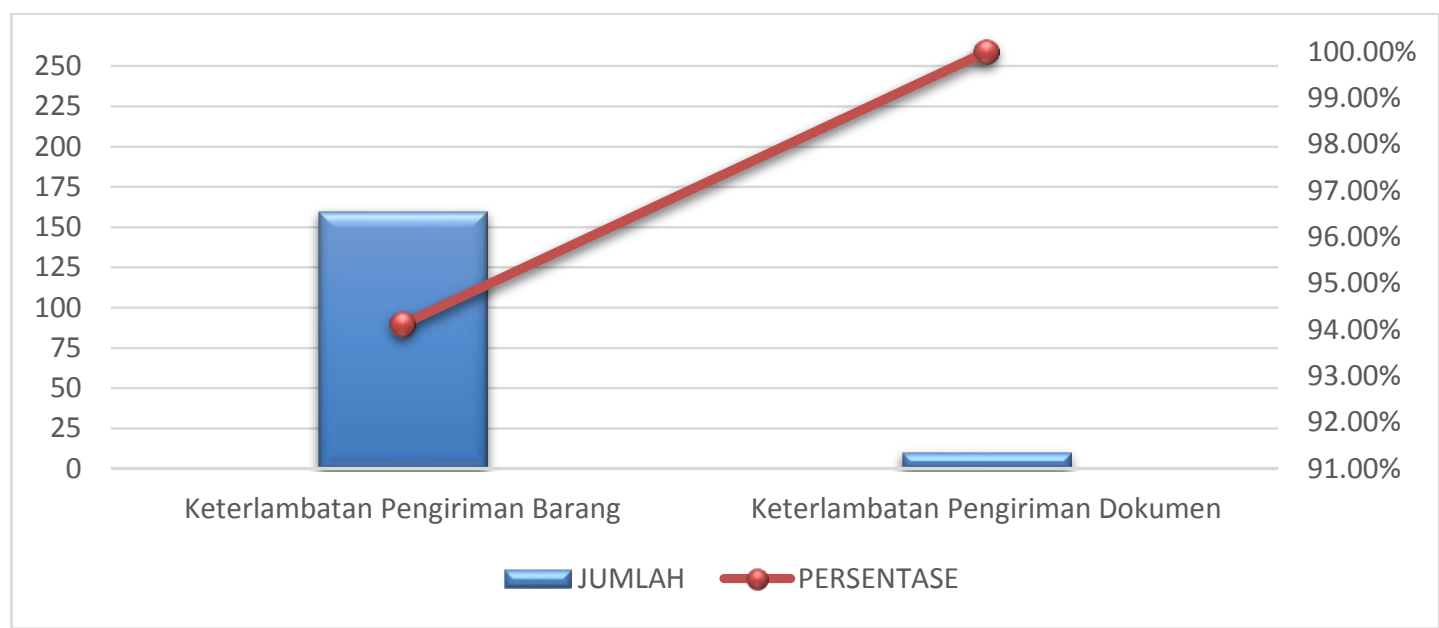

Gambar 3. Diagram Pareto Hasil Identifikasi Masalah Sumber: Hasil Pengolahan Data, Tahun 2020

Analisis Diagram Pareto diatas menunjukkan bahwa frekuensi masalah keterlambatan pengiriman barang lebih besar dari pada keterlambatan pengiriman dokumen dengan besar frekuensi 94\%:6\%. Berdasarkan perbandingan frekuensi tersebut, maka masalah yang akan dianalisis pada tahap selanjutnya yaitu keterlambatan pengiriman barang.

\section{Measure}

a. Perhitungan $D P M O$ dan kapabilitas Sigma

Pada Tabel 2 dapat diketahui bahwa terdapat 634 pengiriman barang dengan total keterlambatan sebanyak 160 kali. Berdasarkan data tersebut, akan dilakukan perhitungan nilai DPMO. DPMO (Defect Per Million Opportunities) yaitu kecacatan per sejuta kesempatan. Perhitungannya dilakukan dengan cara sebagai berikut.

DPO

$$
\begin{aligned}
\mathrm{DPO} & =\frac{\text { Jumlah Kecacatan }}{\text { Jumlah Pengiriman } x \text { peluang }}=\frac{160}{634 \times 1}=0,2524 \\
\mathrm{DPMO} & =\mathrm{DPO} \times 1.000 .000 \\
& =0,2524 \times 1.000 .000 \\
& =252.400
\end{aligned}
$$

Selanjutnya yaitu perhitungan nilai Sigma menggunakan Ms. Excel dengan rumus:

$$
=\text { NORMSINV }(1-D P M O / 1.000 .000)+1,5
$$




$$
\begin{aligned}
& =\operatorname{NORMSINV}(1-252.400 / 1.000 .000)+1,5 \\
& =2,166956=2,17
\end{aligned}
$$

Keterangan: nilai 1,5 merupakan nilai pergeseran variansi untuk level kualitas six sigma. Berdasarkan perhitungan di atas dapat dilihat bahwa DPMO sebesar 252.400 kali per sejuta kesempatan, dengan keterlambatan pengiriman barang sebanyak 160 kali dari total 364 barang yang dikirim. Dengan nilai DPMO sebesar 252.400 maka nilai six sigma nya adalah 2,17 dan peluang bebas kecacatan sebesar 74,77\% yang menggambarkan bahwa peluang suatu proses untuk menghasilkan pengiriman barang yang tepat waktu adalah sebesar $74,77 \%$ atau dengan kata lain tingkat kesalahan dalam pengiriman barang adalah sebesar $25,23 \%$. Dari tingkat kesalahan tersebut maka perlu adanya perbaikan untuk mengurangi tingkat kesalahan yang terjadi.

b. Peta Kendali

Setelah menghitung $C T Q$, diperoleh persentasi keterlambatan yang paling tinggi yaitu keterlambatan pengiriman barang. Selanjutnya akan dilakukan perhitungan dengan menggunakan diagram kendali untuk mengetahui apakah keterlambatan pengiriman barang yang terjadi berada pada batas kendali secara statistik atau tidak. Pada penelitian ini diakukan perhitungan peta kendali dengan menggunakan peta kendali P. Berdasarkan data pada Tabel 2, berikut adalah perhitungan peta kendali P:

1) Persentase keterlambatan setiap bulan:

$$
\begin{array}{lll}
\mathrm{p} \text { September } & =\frac{48}{207} & =0,2319 \\
\mathrm{p} \text { Oktober } & =\frac{61}{233} & =0,2618 \\
\mathrm{p} \text { November } & =\frac{51}{194} & =0,2629
\end{array}
$$

2) Persentase keterlambatan rata-rata atau center (CL) sebagai garis tengah pada diagram kendali:

$$
\mathrm{CL} \quad=\frac{160}{634} \quad=0,2524
$$

3) Batas Kendali Atas atau Upper Control Limit (UCL) dan Batas Kendali Bawah atau Lower Control Limit (LCL):

$$
\begin{array}{lll}
\mathrm{UCL} & =0,2524+3 \frac{\sqrt{0,2524(1-0,2524)}}{634} & =0,2545 \\
\mathrm{LCL} & =0,2524-3 \frac{\sqrt{0,2524(1-0,2524)}}{634} & =0,2503
\end{array}
$$

Berdasarkan perhitungan di atas, perhitungan batas kendali jumlah kiriman dan jumlah keterlambatan dapat dilihat pada tabel berikut:

Tabel 7. Perhitungan Batas Kendali P Keterlambatan

\begin{tabular}{|lcccccc|}
\hline \multicolumn{1}{|c}{ Bulan } & $\begin{array}{c}\text { Jumlah } \\
\text { Kiriman }\end{array}$ & $\begin{array}{c}\text { Jumlah } \\
\text { Keterlambatan }\end{array}$ & P & UCL & CL & LCL \\
\hline September & 207 & 48 & 0,2319 & 0,2545 & 0,2524 & 0,2503 \\
\hline Oktober & 233 & 61 & 0,2618 & 0,2545 & 0,2524 & 0,2503 \\
\hline November & 194 & 51 & 0,2629 & 0,2545 & 0,2524 & 0,2503 \\
\hline
\end{tabular}

Sumber: Hasil Pengolahan Data, Tahun 2020

Berdasarkan data yang ada pada Tabel 7 di atas, dapat dibuat diagram peta control atau peta kendali seperti di bawah ini 




Gambar 4. Peta Kendali P Keterlambatan

Hasil Pengolahan Data, Tahun 2020

Berdasarkan gambar 4 di atas, dapat dilihat bahwa tidak ada yang terkendali. Hal ini menunjukkan bahwa pengendalian keterlambatan pengiriman barang di PT. Z masih mengalami banyak masalah. Oleh sebab itu, diperlukan analisis lebih lanjut mengenai penyebab terjadinya penyimpangan yang terlihat pada peta kendali P. Faktor penyebab proses belum terkendali akan dianalisis dengan menggunakan diagram fishbone.

\section{Analyze}

Pada tahap analisis dilakukan menggunakan diagram fishbone untuk mengetahui akar permasalahan. Fishbone diagram digunakan untuk mencari akar penyebab permasalahan yang terjadi baik penyebab utama maupun akar masalah dari penyebab utama tersebut. Hasil analisis fishbone dapat dilihat pada diagram di bawah ini:

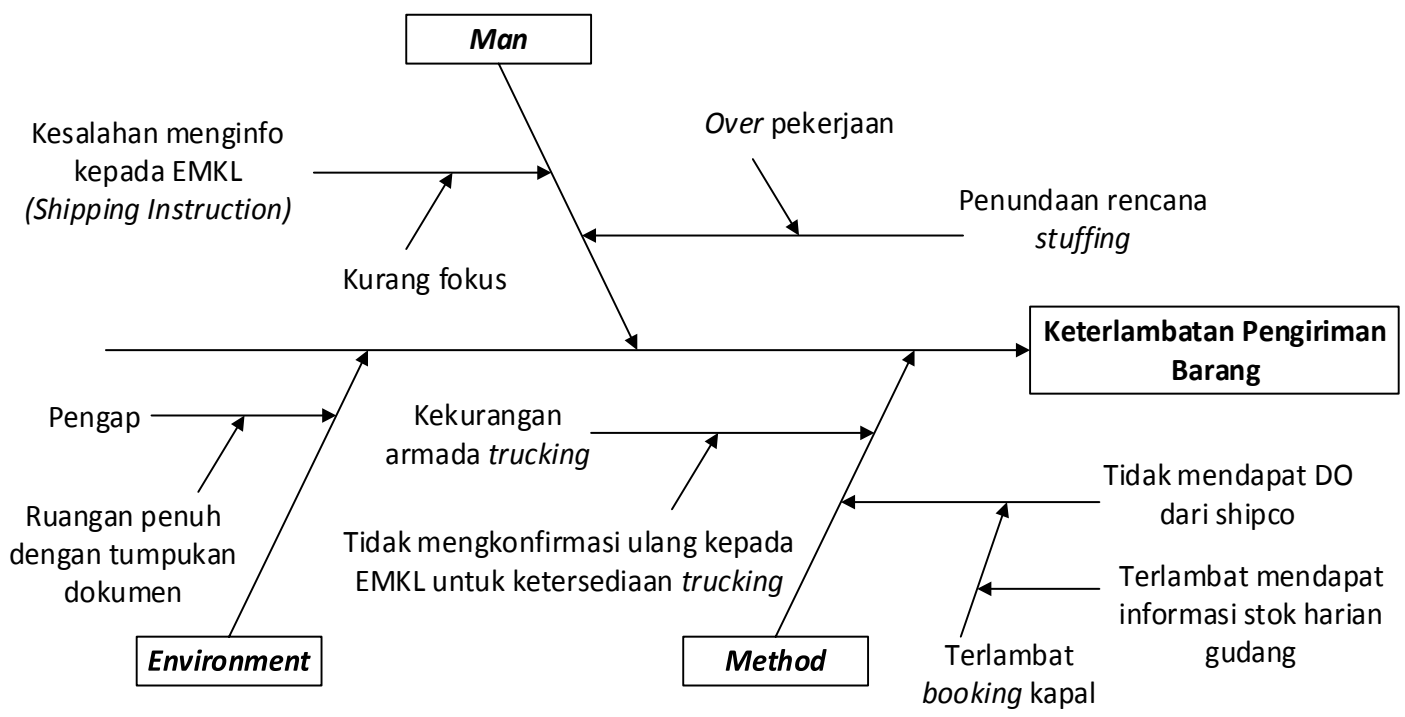

Gambar 6. Analisis Fishbone Diagram

Sumber: Hasil Pengolahan Data, Tahun 2020

Analisis Fishbone Diagram diatas menjelaskan mengenai akar masalah terjadinya keterlambatan pengiriman barang yaitu Method, Man, dan Environment. Berikut penjelasan mengenai Analisis Fishbone Diagram diatas. 
Tabel 8. Analisis Fishbone Diagram Keterlambatan Pengiriman Barang

\begin{tabular}{|c|c|c|}
\hline $\begin{array}{c}\text { Faktor } \\
\text { Penyebab } \\
\text { Masalah } \\
\end{array}$ & Akar permasalahan & Dampak dari Akar Masalah \\
\hline \multirow[t]{2}{*}{ Man } & $\begin{array}{lr}\text { Over pekerjaan } & \text { yang } \\
\text { mengakibatkan } & \text { Penundaan } \\
\text { rencana Stuffing. } & \end{array}$ & $\begin{array}{l}\text { Waktu standar pekerja dalam perusahaan adalah } 8 \\
\text { jam kerja, dalam satu hari dapat mengerjakan tidak } \\
\text { lebih dari } 20 \text { container, namun karena over pekerjaan } \\
\text { mengakibatkan kekurangan man power karena } \\
\text { kelelahan, sehingga rencana stuffing menjadi tertunda } \\
\text { akhirnya stuffing dilakukan dihari berikutnya. }\end{array}$ \\
\hline & $\begin{array}{l}\text { Staf yang kurang fokus } \\
\text { mengakibatkan kesalahan dalam } \\
\text { menginformasikan (Shipping } \\
\text { instruction) kepada EMKL. }\end{array}$ & $\begin{array}{l}\text { Kesalahan menginformasikan (Shipping instruction) } \\
\text { kepada EMKL yang dituju mengakibatkan EMKL } \\
\text { tersebut tidak memproses permintaan PT. Z. Contoh: } \\
\text { seharusnya (Shipping instruction) diberikan kepada } \\
\text { EMKL A namun staf salah mengirimkan kepada } \\
\text { EMKL B }\end{array}$ \\
\hline \multirow[t]{2}{*}{ Method } & $\begin{array}{l}\text { Terlambat mendapat informasi } \\
\text { stock harian } \text { gudang } \\
\text { mengakibatkan terlambat booking } \\
\text { kapal sehingga perusahaan tidak } \\
\text { mendapat DO dari shipco. }\end{array}$ & $\begin{array}{l}\text { Tidak mendapat DO dari shipco mengakibatkan PT } \\
\text { KTI tidak dapat melakukan proses pengiriman } \\
\text { barang. }\end{array}$ \\
\hline & $\begin{array}{l}\text { Tidak menginformasikan ulang } \\
\text { kepada EMKL atas ketersediaan } \\
\text { trucking yang di pesan. }\end{array}$ & $\begin{array}{l}\text { Kekurangan armada trucking mengakibatkan } \\
\text { pengiriman di tunda di hari berikutnya. }\end{array}$ \\
\hline Environment & $\begin{array}{l}\text { Ruangan penuh dengan tumpukan } \\
\text { dokumen mengakibatkan ruangan } \\
\text { kerja menjadi pengap. }\end{array}$ & $\begin{array}{l}\text { Ruangan yang pengap mengakibatkan tidak nyaman } \\
\text { dalam bekerja. }\end{array}$ \\
\hline
\end{tabular}

Sumber: Hasil Pengolahan Data, Tahun 2020

Selain faktor-faktor diatas, dimungkinkan juga penyebab ketelambatan pengiriman barang dipengaruhi juga oleh faktor lain yang belum teridentifikasi dalam penelitian ini. Berdasarkan hasil penelitian karno pada tahun 2012, bahwa faktor penyebab keterlambatan pengiriman barang regular pada PT. Caraka Yasa adalah area gudang belum sebanding dengan jumlah barang yang akan dikirim, kurang termapilnya karyawan dalam mengisi data barang pada sistem yang akan dikirim, dan perusahaan kurang mengadakan pelatihan/seminar yang bertujuan untuk mengasah kemampuan dan keterampilan. Sementara itu berdasarkan penelitian Purba dan Wanda yang dilakukan pada tahun 2014 bahwa penyebab keterlambatan pengiriman barang impor kepada konsumen pada PT UPS Cardig International antara lain yaitu perusahaan tidak melakukan upaya evaluasi kualitas penggunaan waktu kerja yang baik pada karyawan sehingga proses pemeriksaan \& pelengkapan dokumen masih berjalan lambat, masih kurangnya tenaga kerja di bagian operasional dibanding banyaknya pekerjaan yang ada, melakukan update software dan hardware, dan karyawan merasa perolehan upah dan tunjangan kesejahteraan yang mereka dapatkan dari perusahaan masih kurang. Sedangkan menurut penelitian Haryono dan Sri pada tahun 2016, bahwa ada beberapa faktor yang menyebabkan keterlambatan PT Intan Utama Logistik yaitu pencairan dana harus menunggu keputusan GM, jumlah armada operasional yang digunakan untuk menangani kegiatan distribusi terbatas, seluruh proses pengiriman barang harus menggunakan armada transportasi dan sudah menjadi kewajiban untuk mengetahui rute bagi kurir.

\section{Improve}

Pada tahap ini dilakukan setelah melakukan analisis fishbone. Tahap ini menggunakan teknik analisis $5 \mathrm{~W}+1 \mathrm{H}$. Berikut merupakan penjelasan mengenai usulan hasil analisis dengan menggunakan metode $5 \mathrm{~W}+1 \mathrm{H}$ berdasarkan akar masalah pada Fishbone diagram. 
Tabel 9. Analisis $\mathbf{5 W}+\mathbf{1 H}$

\begin{tabular}{|c|c|c|}
\hline Faktor & Uraian & Penjelasan \\
\hline \multirow{6}{*}{$\begin{array}{l}\text { Over pekerjaan } \\
\text { yang } \\
\text { mengakibatkan } \\
\text { Penundaan } \\
\text { rencana Stuffing }\end{array}$} & What & Over pekerjaan \\
\hline & When & $\begin{array}{l}\text { Pada akhir bulan dan saat banyaknya pengiriman yang dapat dilihat } \\
\text { dari jadwal realisasi pengapalan. }\end{array}$ \\
\hline & Where & Gudang export. \\
\hline & Why & $\begin{array}{l}\text { Untuk menghindari penumpukan pengiriman diakhir bulan yang } \\
\text { menyebabkan over pekerjaan, sehingga karyawan menjadi lelah dan } \\
\text { akhirnya rencana stuffing harus ditunda dihari selanjutnya. }\end{array}$ \\
\hline & Who & Karyawan warehouse export. \\
\hline & How & $\begin{array}{l}\text { Menambah pekerja untuk membantu meringankan pekerjaan pada } \\
\text { saat over pekerjaan. }\end{array}$ \\
\hline \multirow{6}{*}{$\begin{array}{l}\text { Staf yang kurang } \\
\text { fokus } \\
\text { mengakibatkan } \\
\text { kesalahan dalam } \\
\text { menginformasika } \\
\text { n (Shipping } \\
\text { instruction) } \\
\text { kepada EMKL }\end{array}$} & What & Staf yang kurang fokus. \\
\hline & When & Saat order trucking kepada EMKL. \\
\hline & Where & Ruang divisi marketing. \\
\hline & Why & $\begin{array}{l}\text { Agar staf tidak salah dalam menginformasikan (Shipping } \\
\text { instruction) kepada EMKL. }\end{array}$ \\
\hline & Who & Staf administrasi pengiriman. \\
\hline & How & $\begin{array}{l}\text { Karyawan harus tetap fokus walaupun banyak dokumen yang } \\
\text { dikirimkan kepada EMKL sesuai dengan instruksi pembagian order } \\
\text { dari atasan. }\end{array}$ \\
\hline \multirow{6}{*}{$\begin{array}{l}\text { Terlambat } \\
\text { mendapat } \\
\text { informasi stock } \\
\text { harian gudang } \\
\text { mengakibatkan } \\
\text { terlambat booking } \\
\text { kapal sehingga } \\
\text { tidak mendapat } \\
\text { DO dari shipco. }\end{array}$} & What & Terlambat mendapat informasi stock harian gudang \\
\hline & When & Perbaikan perlu dilakukan secara terus-menerus. \\
\hline & Where & Ruang divisi marketing. \\
\hline & Why & Agar tidak terlambat booking kapal. \\
\hline & Who & Staf administrasi pengiriman. \\
\hline & How & $\begin{array}{l}\text { Menjalin interaksi secara aktif antara staf administrasi pengiriman } \\
\text { dengan admin gudang supaya segera mendapat informasi stock } \\
\text { gudang. }\end{array}$ \\
\hline \multirow{6}{*}{$\begin{array}{l}\text { Tidak } \\
\text { menginformasika } \\
\text { n ulang kepada } \\
\text { EMKL atas } \\
\text { ketersediaan } \\
\text { trucking yang di } \\
\text { pesan } \\
\text { mengakibatkan } \\
\text { kekurangan } \\
\text { armada trucking. }\end{array}$} & What & $\begin{array}{l}\text { Tidak mengkonfirmasi ulang kepada EMKL atas ketersediaan } \\
\text { armada trucking. }\end{array}$ \\
\hline & When & Perbaikan perlu dilakukan secara terus-menerus. \\
\hline & Where & Ruang divisi marketing. \\
\hline & Why & Agar tidak kekurangan armada trucking. \\
\hline & Who & Staf administrasi pengiriman. \\
\hline & How & $\begin{array}{l}\text { Staf administrasi pengiriman mengkonfirmasi ulang kepada pihak } \\
\text { EMKL untuk kesiapan trucking pengiriman di hari berikutnya } \\
\text { sesuai dengan jadwal agar terhindar dari kekurangan trucking dan } \\
\text { pada saat mengetahui kekurangan trucking sebaiknya segera untuk } \\
\text { mencari EMKL lain agar barang dapat dikirim. }\end{array}$ \\
\hline \multirow{3}{*}{$\begin{array}{l}\text { Ruangan yang } \\
\text { penuh dengan } \\
\text { tumpukan }\end{array}$} & What & Ruangan penuh dengan tumpukan dokumen \\
\hline & When & Perbaikan dapat dilakukan sesegera mungkin. \\
\hline & Where & Ruang divisi marketing. \\
\hline
\end{tabular}

\section{Control}

Pada tahap yang terakhir adalah control, yang merupakan pengendalian dari tahapan analisis. Pada tahap ini akan digunakan Standar Operational Procedure (SOP) yang dibuat ditujukan kepada seluruh orang-orang yang terlibat, terutama kepada bagian marketing yang menangani pengiriman barang. Sehingga keterlambatan pengiriman barang dapat diminimalisir. Berikut adalah SOP yang dapat diaplikasikan pada PT. Z. 
Tabel 10. Standar Operational Procedure

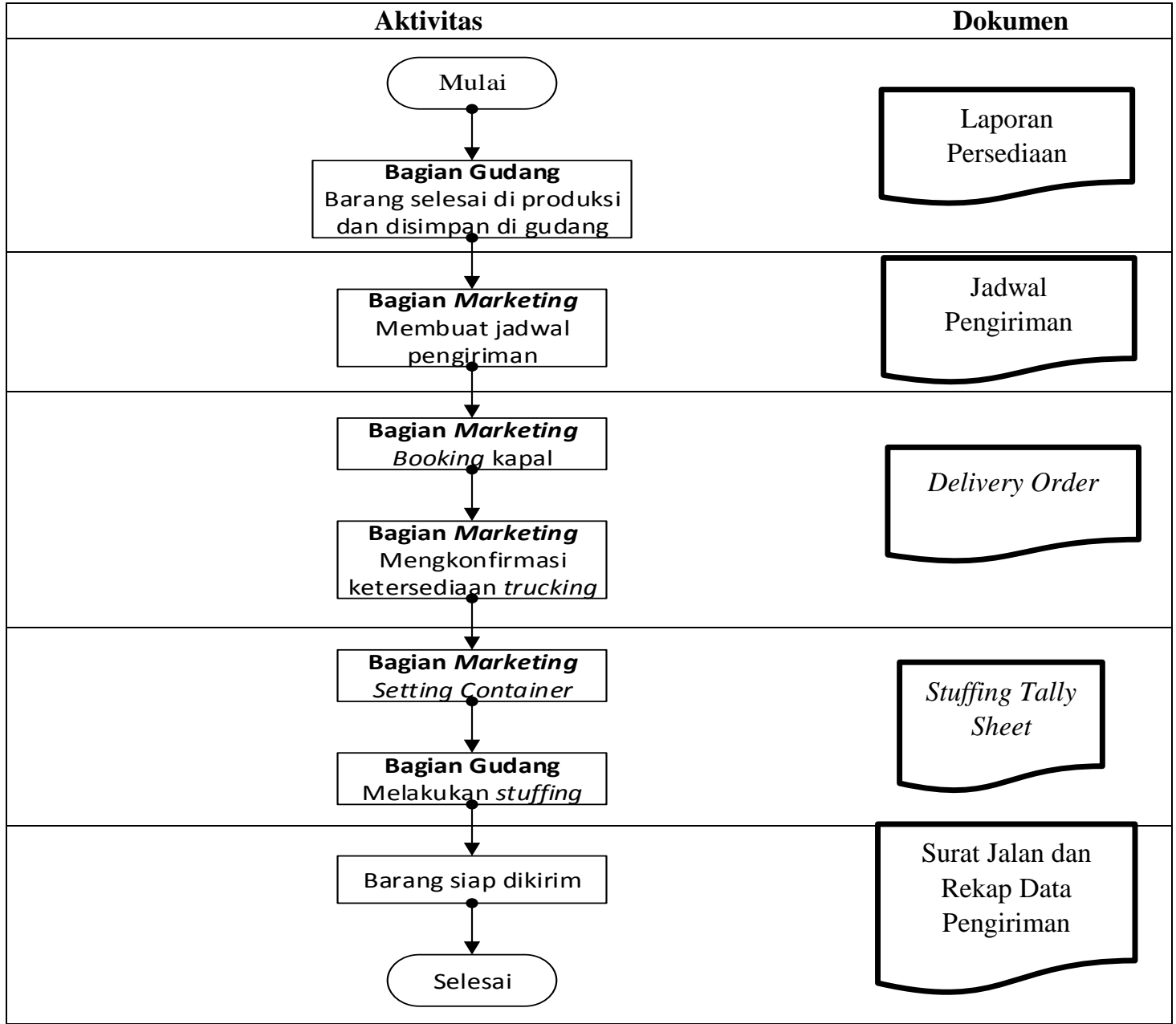

Sumber: Hasil Pengolahan Data, Tahun 2020

Berdasarkan tabel di atas dapat diketahui proses pengiriman barang serta dokumen yang terkait bahwa bagian gudang yaitu memastikan barang yang akan dikirim sesuai dengan purchase order dan driver membawa dokumen sesuai dengan barang yang dibawa. Sedangkan bagian marketing yakni melakukan booking kapal seminggu sebelum pengiriman dan memastikan jadwal pengiriman sudah sesuai dengan purchase order.

\section{KESIMPULAN}

Berdasarkan hasil analisis yang dilakukan maka dapat disimpulkan bahwa jenis keterlambatan yang sering terjadi yakni keterlambatan pengiriman barang. Keterlambatan pengiriman barang disebabkan oleh over pekerjaan yang mengakibatkan penundaan rencana stuffing, staf yang kurang fokus mengakibatkan kesalahan dalam menginformasikan shipping instruction kepada EMKL, terlambat mendapat informasi stock harian gudang sehingga terlambat booking kapal, tidak menginformasikan ulang kepada EMKL atas ketersediaan trucking yang dipesan sehingga kekurangan armada trucking, dan menumpuknya dokumen di ruang kerja. Adapun rencana tindakan perbaikan guna meminimalisir terjadinya keterlambatan pengiriman barang yaitu pertama, menambah pekerja untuk membantu meringankan pekerjaan pada saat over pekerjaan. Kedua, karyawan harus tetap fokus walaupun banyak dokumen yang dikirimkan kepada EMKL sesuai dengan instruksi pembagian order dari atasan dan sebaiknya karyawan menyelesaikan satu tugas terlebih dahulu sebelum mengerjakan tugas lain sehingga penyelesaian tugas dilakukan secara bertahap. Ketiga, menjalin interaksi yang aktif antara staf administrasi pengiriman dengan admin gudang supaya segera mendapat informasi stock gudang. Keempat, staf administrasi pengiriman mengkonfirmasi ulang kepada pihak EMKL untuk kesiapan trucking pengiriman dihari berikutnya 
sesuai dengan jadwal agar terhindar dari kekurangan trucking. Pada saat mengetahui kekurangan tersebut sebaiknya segera mencari EMKL lain agar barang dapat dikirim. Terakhir, mengelompokkan dokumen yang sudah dikerjakan dan diletakkan di ruangan terpisah sehingga ruang kerja menjadi rapi dan nyaman.

\section{DAFTAR PUSTAKA}

J. E. Panjaitan and A. L. Yuliati, "Pengaruh Kualitas Pelayanan Terhadap Kepuasan Pelanggan Pada JNE Cabang Bandung," DeReMa (Development Res. Manag. J. Manaj., vol. 11, no. 2, pp. 265-289, 2016.

S. Somadi and F. Hidayat, "Rancangan Strategi Untuk Mengatasi Penolakan Truk Dan Kontainer Oleh Customer," J. Logistik Bisnis, vol. 9, no. 2, pp. 118-124, 2019, doi: http://dx.doi.org/10.46369/logistik.v9i02.574.

Somadi, B. S. Priambodo, and P. R. Okarini, "Evaluasi Kerusakan Barang Dalam Proses Pengiriman Dengan Menggunakan Metode Seven Tools," J. INTECH Tek. Ind. Univ. Serang Raya, vol. 6, no. 1, pp. 1-11, 2020, doi: http://dx.doi.org/10.30656/intech.v6i1.2008.

R. E. Haryanto, "Logistik dan Layanan Pelanggan," Supply Chain Indonesia, Bandung, pp. 1-4, 2017.

D. R. L. Utami, Mustafid, and R. Rahmawati, "Six Sigma Untukk Analisis Kepuasan Pelanggan Terhadap Persepsi Kualitas Provider Kartu GSM Prabayar," J. Gaussian, vol. 4, no. 1, pp. 21-31, 2015.

H. Sirine and E. P. Kurniawati, "Pengendalian Kualitas Menggunakan Metode Six Sigma (Studi Kasus pada PT Diras Concept Sukoharjo)," AJIE-Asian J. Innov. Entrep., vol. 02, no. 03, pp. 2477-3824, 2017.

D. S. Nyata and I. P. A. Wiguna, "Analisis Keterlambatan pada Proyek PT Jatim Taman Steel di Gresik dengan Menggunakan Lean Six Sigma Framework," J. Apl. Tek. Sipil, vol. 16, no. 1, pp. 15-22, 2018.

H. Fransiscus, C. P. Juwono, and I. S. Astari, "Implementasi Metode Six Sigma DMAIC untuk Mengurangi Paint Bucket Cacat di PT X," J. Rekayasa Sist. Ind., vol. 3, no. 2, pp. 53-64, 2014.

S. Somadi and U. Usnandi, "Pengendalian Kualitas Starter Clutch Dalam Upaya Mengurangi Product Defect di PT XYZ: Pendekatan DMAIC," JBME J. Bisnis Manaj. Ekon., vol. 17, no. 2, pp. 120-139, 2019.

S. Somadi, B. S. Priambodo, and P. R. Okarini, "Evaluasi Kerusakan Barang Dalam Proses Pengiriman Dengan Menggunakan Metode Seven Tools," J. Intech Tek. Ind. Univ. Serang Raya, vol. 6, no. 1, pp. 1-11, 2020.

S. Somadi and F. Hidayat, "Rancangan Strategi Untuk Mengatasi Penolakan Truk Dan Kontainer Oleh Customer," J. Logistik Bisnis, vol. 9, no. 2, pp. 118-124, 2019, doi: 10.46369/logistik.v9i02.574.

Karno, "Faktor-Faktor Penyebab Keterlambatan Pengiriman Barang Reguler Dari Gudang Pusat Ke Consignee Pada Jasa Courier Domestik PT. Caraka Yasa Jakarta Tahun 2012," Jurnal Manajemen. pp. 84-88, 2012.

O. R. Purba and J. Wanda, "Penyebab Keterlambatan Pengiriman Barang Impor Pada Customer," J. Manaj. Bisnis Transp. dan logistik, vol. 1, no. 1, pp. 42-59, 2014.

Haryono and L. M. Sari, “Analisis Faktor Penyebab Keterlambatan Pengiriman Produk Arnotts Ke Alfamart Area Jabodetabek Dan Banten Pt Intan Utama Logistik Tahun 2015," J. Manaj. Bisnis Transp. Dan Logistik, vol. 3, no. 1, pp. 11-20, 2016. 